\title{
Pedagogía del oprimido: escrito dirigido al opresor
}

Pedagogy of the Oppressed: A Text to the Oppressor

José Oliverio Tovar-Bohórquez

Universidad Nacional de Colombia (Colombia)

Recibido: 2014-08-26

Envío a pares: 2014-08-27

Aprobado por pares: 2014-11-10

Aceptado: 2014-11-11

Pensamiento y Cultura | ISSN: 0123-0999 | elSSN: 2027-5331

pensam.cult | Vol. 18-1 | Junio de 2015 | pp. 155-173

DOI: 10.5294/pecu.2015.18.1.6 


\section{Pedagogía del oprimido: escrito dirigido al opresor}

Resumen: Paulo Freire sostiene que en la relación entre el opresor y el oprimido es este último quien tiene la responsabilidad de iniciar el proceso de emancipación y, al hacerlo, debe comprometerse con la liberación del opresor. El objetivo del presente artículo es mostrar, a partir de los argumentos esgrimidos por Freire y en oposición a su propia teoría, que es en el opresor en quien recae la responsabilidad de iniciar dicho proceso de liberación. Posteriormente, se hará una reflexión en torno a los efectos que tendría esta nueva interpretación aplicada a un tema fundamental para Freire, a saber, la colonización.

Palabras clave: filosofía de la educación; educador; educando; liberación; colonización.

\section{Pedagogy of the Oppressed: A Text to the Oppressor}

Abstract: With respect to the relationship between the oppressor and the oppressed, Paulo Freire argues it is the latter who is responsible for initiating the process of emancipation and, in doing so, must be committed to liberating the oppressor. Based on Freire's arguments and in opposition to his theory, this article is intended to show it is the oppressor who bears the responsibility for initiating the process of liberation. The article also reflects on the effects this new interpretation would have if applied to what is a fundamental issue for Freire: colonization.

Keywords: Philosophy of education; educator; student; liberation; colonization.

\section{Introducción}

En la Pedagogía del oprimido -obra magna de Paulo Freire-, el autor presenta su concepción filosófica sobre educación (Aronowitz 1993, 8, citado por Bartlett 2005, 28), la cual tiene como propósito defender una propuesta alternativa a la práctica pedagógica tradicional para construir un aula que propenda por la liberación de los sujetos. Este objetivo se mantiene a lo largo de sus libros posteriores sin mayores cambios (Beckett 2013, 50).

Así, el autor brasileño construye su propuesta filosófica sobre la relación opresor-oprimido (McLaren 2000, 156, citado por Bartlett 
$2005,33)$ y lo hace de manera tal que el oprimido tiene la responsabilidad de liberarse a sí mismo y, al hacerlo, liberar al opresor. Si en su proceso de liberación no logra esto último (liberar al opresor), caerá en lo que Freire denomina la "contradicción opresor-oprimido". El trabajo de Freire está dedicado y dirigido al oprimido (no al opresor), pues el autor se alinea con el compromiso que aquel tiene de alcanzar su liberación; dicho de otra manera, en sus escritos, el pedagogo brasileño construye un diálogo con el oprimido, no con el opresor, no con el sectario. Sobre esto último dice: "La pedagogía del oprimido que implica una tarea radical, y cuyas líneas introductorias intentamos presentar en este ensayo, implica también que la lectura misma de este libro no pueda ser desarrollada por sectarios" (Freire 2005, 34).

En la educación bancaria - término acuñado por Freire para representar la dinámica tradicional de la educación-, el papel de opresor lo tendrá el docente, mientras que el estudiante será el oprimido, toda vez que el primero, además de ocupar el poder total dentro del aula, considera al segundo no más que como un banco al que debe llenar de información. La tarea del educando, por su parte, se restringe a "recibir los depósitos, guardarlos y archivarlos” (Freire 2005, 78). En su obra, como ya se insinuó, Freire propone pasar de una educación bancaria a una educación liberadora. Para ello, el educador deberá experimentar un proceso de transformación que lo conducirá a la liberación, lo cual le permitirá transformar su aula y, así, liberar al estudiante (Beckett 2011a, 2011b, citado por Beckett 2013, 50).

Hemos dicho que, en la relación opresor-oprimido, quien tiene la responsabilidad de la liberación es este último. En contraste con la teoría freireana, el propósito del presente ensayo es mostrar que en el aula de clase la responsabilidad de la liberación recae en el opresor y no en el oprimido; pues el opresor, que es el educador, será el responsable de liberarse a sí mismo y, al hacerlo, liberar al oprimido, que es el educando. Lo anterior implicaría, al contrario de los deseos de Freire, que la Pedagogía del oprimido estaría dirigida al opresor, toda vez que gran parte del trabajo del pedagogo brasileño está dirigido al educador; a un educador que, estando instalado en la educación bancaria, debe luchar para llegar a ser un educador humanista, expresión esta que utiliza 
Freire en referencia al educador que busca constantemente la liberación de ambos: educador y educando.

En lo que sigue, primero, haré una presentación sintética de la teoría freireana; segundo, expondré el argumento con el que pretendo mostrar que - siendo consistentes con la propuesta de Freire- la responsabilidad de la liberación recae en el opresor; tercero, aplicaré esta reinterpretación de la propuesta de Freire al tema de la colonización, tema por el que también se interesó el autor brasileño (Giroux 1993 y Margonis 2000).

\section{La contradicción opresor-oprimido}

La vocación de los hombres es la humanización, la cual se expresa en su ansia de libertad y de justicia. El hombre teme a la libertad, aunque no tiene conciencia de este padecimiento. El temor a la libertad no le permite luchar por su humanización, impidiéndole, así, ejercer su vocación. Podría decirse que este es, a muy grandes rasgos, el problema del que parte Freire para construir su pedagogía del oprimido.

El temor a la libertad es producto de un deseo por vivir seguro con lo que se tiene. Es decir, el temor a la libertad es un temor a perder lo que se tiene asegurado, sin importar si es poco (Freire 2005, 30). Teme a la libertad quien no se siente capaz de correr el riesgo de asumirla (Freire $2005,46)$. Dado que normalmente no se tiene conciencia de este temor, lo que suelen hacer las personas es camuflarlo presentándose a sí mismas como sujetos que defienden la libertad y no como personas que la temen.

Una de las fuentes del miedo a la libertad es la prescripción. La prescripción es uno de los elementos básicos que media la relación opresor-oprimido, ya que el comportamiento del oprimido es guiado por pautas (prescripciones) impuestas por el opresor (Freire 2005, 45, 46, 62; Freire 1970, 149, 155, 180; Freire 1984, 72). Para ser libre se requiere suprimir las pautas del otro, del opresor, lo cual generaría un vacío (carencia de prescripciones). El oprimido teme a este vacío, pues siente que no sabe cómo llenarlo (Freire 2005, 45). Excepto aquel que corre el riesgo y asume la tarea de llenarlo preparándose para imponerse a sí mismo sus propias pautas, los oprimidos prefieren seguir las prescripciones impuestas por el opresor. Así, ellos permanecerán en su estado 
de opresión indefinidamente y, en caso de que salgan de él, pasarán a ser opresores, dados los preceptos que siempre los han regido.

Según lo anterior, debido a las pautas que los han guiado en su historia de vida, los oprimidos enfrentan una "contradicción opresoroprimido" de la que les es difícil escapar. Ellos asumen una postura de "adherencia" al opresor, la cual los conduce, en su búsqueda por la liberación, a una identificación con su contrario (Freire 2005, 43). En efecto, los oprimidos que no han hecho una reflexión rigurosa sobre su condición encuentran en la opresión su camino a la liberación. Es decir, el oprimido comúnmente cree que la manera de salir de su estado de opresión es convirtiéndose en opresor. "Para ellos el hombre nuevo son ellos mismos, transformándose en opresores de otros" (Freire 2005, 44, énfasis del autor). En este sentido, los oprimidos asumen erróneamente que el opresor está liberado. No obstante, esta asunción es falsa, el opresor no está liberado, toda vez que en su acto de opresión deshumaniza al oprimido, con lo cual se deshumaniza a sí mismo. La opresión implica deshumanización y, por tanto, no puede ser vista en ninguna circunstancia como un camino a la liberación. El oprimido, entonces, cae en una contradicción porque, al adherirse al opresor, mantiene el estado de opresión que, inicialmente, deseaba acabar.

De lo anterior se infiere que una de las condiciones necesarias para que el oprimido se libere, se humanice, es la de generar prescripciones propias que guíen su comportamiento; esto es, para decirlo en términos kantianos (Kant, 1784/1978), que sea autónomo. Dado que la liberación no consiste en llegar a ser opresor, estas nuevas prescripciones autoimpuestas no deben, en ninguna circunstancia, promover la opresión.

La Pedagogía del oprimido - escrito a partir del trabajo de campo realizado por el autor brasileño- es elaborada con, no para, el oprimido, a fin de que él mismo reflexione en torno a su estado de opresión y luche en comunidad por su liberación. Esto implica que también habrá de luchar por la liberación de los opresores, en la medida en que la lucha por la liberación exige una lucha permanente por la recuperación de la humanidad de los dos. Así es como el oprimido podrá resolver la contradicción a la que se enfrenta. El "hombre nuevo", entonces, no será un opresor, como asume erradamente el oprimido, sino un hombre 
liberándose (Freire 2005, 47). Permítanme insistir con otras palabras, siguiendo la teoría freireana, el hombre nuevo es el oprimido luchando por su propia liberación, siguiendo al autor brasileño, es el oprimido quien tiene la responsabilidad de iniciar el proceso de descolonización, de emanciparse del yugo del opresor.

Ahora bien, no es suficiente que los oprimidos sean conscientes de la situación en la que se encuentran y que reflexionen en torno a ella, además es necesario que actúen para lograr su liberación. Tampoco es suficiente que actúen -digamos-impulsivamente, pues la acción sin reflexión redundará en una lucha deshumanizadora. La reflexión sobre su condición de opresión debe ir necesariamente acompañada de la acción, solo así los oprimidos lograrán liberarse. A la acción que, acompañada de reflexión, busca transformar el mundo para lograr la liberación, Freire la llama praxis liberadora. Salir del estado de opresión implica una búsqueda permanente de la libertad. Entonces, es mediante la praxis que los hombres podrán mantenerse en la búsqueda permanente de su liberación, lo cual responde justamente a su vocación de "ser más", a su vocación ontológica e histórica, a su humanización.

De acuerdo con el concepto de 'praxis' introducido por Freire, la contradicción opresor-oprimido podría entenderse de la siguiente manera: cuando el oprimido, al buscar su liberación, lucha por adquirir el lugar de opresor cae en una contradicción porque su acto carece de reflexión. Solo esta, la reflexión, le permitirá caer en la cuenta de que ser opresor también es deshumanizante.

La lucha con la que los oprimidos responden a la violencia de los opresores no tiene como fin la dominación, por ello es considerada un legítimo acto de amor, acto que nace en un diálogo mediante el cual cada una de las partes está dispuesta a transformar el mundo mancomunadamente; diálogo que es utilizado para conquistar el mundo en comunión, pero nunca para conquistar a la persona (Freire 2005, 70 y la nota al pie 5 de la p. 8). Al respecto dice Freire:

Es así como no hay diálogo si no hay un profundo amor al mundo y a los hombres. No es posible la pronunciación del mundo, que es un acto de creación y recreación, si no existe amor que lo infunda. 
Siendo el amor fundamento del diálogo, es también diálogo. De ahí que sea, esencialmente, tarea de sujetos y que no pueda verificarse en la relación de dominación. En ésta, lo que hay es patología amorosa: sadismo en quien domina, masoquismo en los dominados. Amor no. El amor es un acto de valentía, nunca de temor; el amor es compromiso con los hombres. Dondequiera que exista un hombre oprimido, el acto de amor radica en comprometerse con su causa. La causa de su liberación. Este compromiso, por su carácter amoroso, es dialógico.

Como acto de valentía, no puede ser identificado con un sentimentalismo ingenuo; como acto de libertad, no puede ser pretexto para la manipulación, sino que debe generar otros actos de libertad. Si no es así no es amor.

El diálogo es el encuentro entre humanos, mediado por el mundo, para pronunciar el mundo (Freire 2005, 105; Bartlett 2005, 346). El diálogo está constituido por la palabra; la palabra es el diálogo mismo - dice Freire- y esta, si es verdadera, estará constituida por la praxis (acción y reflexión), pues decir la palabra verdadera implica transformar el mundo (Freire 2005, 105). Por tanto, si la palabra carece de alguna de sus dos dimensiones (acción o reflexión) es inauténtica. En un caso, cuando carece de acción, es mera superchería, en la medida en que carece de actos que transformen el mundo; en el otro se convertirá en activismo, en acción por la acción, con lo cual se cerrará la posibilidad del diálogo. Las personas se hacen, se desarrollan, mediante el diálogo, que es acción y reflexión, nunca mediante el silencio. Por ello, pronunciar el mundo, decir la palabra verdadera, que es transformar el mundo, no es privilegio de algunas personas, sino un derecho de todas (Freire 2005, 107). La primera tarea de los oprimidos es luchar para adquirir el derecho a pronunciar el mundo. Este no es un derecho a imponer una verdad, sino a transformar el mundo con los otros, a crearlo y recrearlo, a problematizarlo; de nuevo, a conquistarlo en comunión. La vocación de "ser más", la cual implica una búsqueda permanente por la liberación, requiere un trabajo que no se puede hacer individualmente, sino que se realiza en solidaridad con los demás (Walsh 2013, 86) mediante un encuentro dialógico. 
Hay opresores que consideran a los oprimidos como personas y, en cuanto tal, los consideran libres. No obstante, si el opresor no hace nada para lograr que esta consideración (mera declaración) sea objetiva, que se refleje en la realidad, será una mera patraña. El opresor se solidariza con el oprimido cuando su gesto deja de ser ególatra, cuando se abstiene de buscar en cada acto su propio beneficio y pasa a realizar un acto de amor. Esto es, cuando los oprimidos dejan de ser para él una designación abstracta y pasan a ser personas concretas; personas que han sido despojadas de su palabra, que se encuentran en una situación de injusticia y que son objeto de comercialización.

Dicho de otro modo, el oprimido experimenta en carne viva y a diario su situación de opresión, lo cual implica que la solidaridad del opresor - si es genuina - se deberá poder verificar objetivamente, pues deberá producir una transformación en el mundo. Una transformación que, por medio del diálogo, contribuya a la liberación del oprimido.

Respecto de la praxis liberadora se puede establecer una contradicción, en este caso, experimentada por el opresor. En efecto, cuando él, el opresor, piensa que el oprimido es libre y aun así mantiene el estado de opresión, cae en una contradicción porque su reflexión (aquella que le permite darse cuenta de que el oprimido es un ser humano y, en cuanto tal, un ser con ansia de libertad) no corresponde con su acción.

\section{La contradicción educador-educando}

De acuerdo con la concepción bancaria, propuesta por Freire, la educación es vista como el acto de depositar, narrar, transferir o transmitir conocimientos y valores a los educandos, concebidos como meros pacientes (Freire 2005, 58). La contradicción opresor-oprimido, a la que ya se hizo referencia, la encontramos en el aula de clase bajo la relación educador-educando. Esta relación se teje por medio de la narración, la cual reduce al educando a un mero recipiente en el que se deposita información. La labor del educador consiste en dar un discurso que deberá ser memorizado mecánicamente por el estudiante.

En la concepción bancaria de la educación, el saber, el conocimiento, es visto como una donación del educador, que se juzga sabio, 
al educando, juzgado como inculto. Esta donación, dice Freire, se basa en una de las manifestaciones instrumentales de la ideología de la opresión: la alienación, o absolutización, de la ignorancia, "según la cual ésta se encuentra siempre en el otro" $(2005,79)$.

En la educación bancaria, el educador es el que piensa, el que sabe, el que disciplina, el que prescribe, el que actúa, el que escoge el contenido programático. El estudiante es su antagonista, es el objeto pensado, el disciplinado, el que sigue la prescripción. El estudiante no actúa, porque no participa en la construcción del conocimiento, mucho menos colabora en la elección del contenido programático (Freire 2005, 80). En esta concepción tradicional de la educación, la discusión en el aula es monológica y se reduce estrictamente a la visión de mundo del educador (Beckett 2013, 50).

¿Qué es aquello que sabe el docente y que ignora el estudiante? La concepción bancaria de la educación se sostiene sobre una falsa visión del ser humano, una que considera que hay una dicotomía entre el hombre y el mundo, según la cual las personas están capacitadas para recibir información del mundo, pero no para transformarlo ni recrearlo. Esto se debe a que se considera la conciencia como un mecanismo pasivo, cuya única función es la de recibir permanentemente la información que el mundo deposita en ella (Freire 2005, 84). Entonces - al no haber creadores sino solo espectadores-, se tiene un mundo sin dinámica, fraccionado y bien organizado y una mente que lo conoce.

El docente, por su formación, conoce fragmentos de dicho mundo y deposita su conocimiento en el estudiante para que este lo guarde y archive. El problema es que bajo esta noción de conocimiento tanto el docente como el estudiante devienen autómatas, renuncian a la praxis, dejan a un lado la búsqueda de la liberación que, como ya se dijo, debe ser permanente. En pocas palabras, el problema es que la concepción bancaria de la educación conduce a la negación de su vocación de humanizarse, de ser más. La contradicción educador-educando, en la que el primero (educador) es el antagonista del segundo, debe ser enfrentada con el fin de lograr la liberación de los dos.

Lo que buscan los opresores, dice Freire, "es transformar la mentalidad de los oprimidos y no la situación que los oprime", para que se 
adapten mejor a la situación, lo cual permitirá una mejor forma de dominación (Freire 2005, 81). Los opresores consideran a los oprimidos como seres marginados, seres inadaptados; son una patología de las sociedades sanas, un problema que estas deben remediar. La solución es transformar sus mentalidades de hombres ineptos y perezosos para que puedan integrarse a la sociedad sana.

Esta concepción evidentemente es equivocada, los oprimidos no son seres marginados, no son seres que estén fuera de. Son seres que se encuentran dentro de una estructura que los transforma en seres para otro. La solución para los oprimidos no está, entonces, en integrarse a esta estructura, sino en transformarla con el fin de que puedan convertirse en seres para sí, esto es, en seres capaces de regirse por sus propias leyes (Freire 2005, 82), lo cual es posible porque la conciencia no es un mecanismo especializado, cuya única función es recibir los depósitos del mundo; no hay una zona específica en el cerebro o en el cuerpo en la que se encuentre la conciencia. Somos, dice Freire, "cuerpos consientes", no estamos en el mundo, sino con el mundo, en la medida en que lo transformamos, lo recreamos. No somos entes pasivos, no somos meros espectadores, somos agentes capacitados para conectarnos con el mundo y con los otros y, así, construir nuevos mundos. El medio idóneo para lograr la transformación es la educación, pero la actitud opresora de los docentes incrustados en la educación bancaria impide que tal transformación se dé. Por ello, se mantendrá la contradicción educador-educando en la que, finalmente, los dos resultan siendo autómatas.

El educador humanista, dice Freire, es el responsable de romper tal contradicción (sobre las exigencias que debe cumplir un educador humanista se puede ver Freire 1997 y Freire 2010). Es educador humanista aquel que confía sinceramente en el poder creador de los otros. Partiendo de esto, su labor consistirá en buscar la liberación de ambos, de él y de sus estudiantes, y para ello deberá identificarse con ellos, educarse con ellos, convertirse en su compañero. Esto último, ser su compañero, es necesario, pues en el momento en el que surja este compañerismo, construido mediante el diálogo, el educador dejará de hacer depósitos, de hacer prescripciones, dejará de domesticar al educando. En este proceso, las dos partes, educador y educando, dejarán 
de ser meros autómatas y pasarán a construir en comunidad su conocimiento (Freire y Macedo 1987, 41; Freire, Gadotti y Guimaraes 1987, 76). Así, finalmente, el educador pasará a ser un educador-educando y los educandos pasarán a ser educandos-educadores, en la medida en que los dos en comunión serán los responsables del proceso educativo mediante el cual todos crecerán; proceso que estará mediado por el mundo (Freire 2005, 92).

De esta manera, al trabajar con el profesor para problematizar el mundo, el estudiante ya no se verá como un ente pasivo ante un mundo estático que se le presenta, sino como un agente activo, capaz de transformar la realidad, realidad que ahora se le presenta como constantemente cambiante. Incluso la historia es susceptible de ser reescrita cuando se la lee y comprende en diálogo con los otros. Una lectura crítica del pasado les permitirá a los sujetos investigadores comprender de manera más clara qué y quiénes son, lo cual, unido al hecho de que la realidad ya no es vista como estática, les permitirá ser conscientes de que interpretando su historia podrán construir un mejor futuro (Freire 2005, 98; Beckett 2013, 51).

El docente que pretenda llevar a cabo la búsqueda de la liberación a través de la concepción bancaria prolongará la contradicción. La liberación, insistimos, es una búsqueda permanente, es humanización en proceso, no una cosa que se deposita en las mentes de los estudiantes (Freire 2005, 90). La liberación no es una palabra más que los estudiantes deben memorizar. La liberación es praxis, lo cual implica que una educación que promueva la liberación no puede, en ningún aspecto, consistir exclusivamente en el depósito de contenidos. Así, la educación que imparta el docente deberá estar guiada por el ejemplo, es decir, no será suficiente su palabra, sino que también será necesario que su palabra sea coherente con sus actos, de lo contrario, la credibilidad en lo que él dice se desvanecerá (Freire 2010, 98).

El diálogo, como ya es evidente, desempeña un papel fundamental en el proceso de liberación que habrán de tener docente y alumno. Ahora, dar preponderancia al diálogo no implica que se esté impidiendo que haya momentos explicativos o narrativos por parte del profesor en el aula de clase. Estos sin duda se mantendrán, lo realmente importante es que las 
dos partes, profesor y estudiante, adopten conscientemente una postura indagadora, en la que la curiosidad guíe su diálogo. Lo importante es que profesores y estudiantes se asuman como seres epistemológicamente curiosos (Freire 2010, 127; 1997, 83). La tarea del docente incluirá, entonces, generar un ambiente en el aula que motive a los estudiantes a despertar su curiosidad por los temas tratados, lo cual generará una discusión en la que el docente mismo se verá llevado a investigar nuevos asuntos. Sobre esto último, es fundamental tener presente que una de las exigencias que Freire hace al docente es la responsabilidad máxima que él tiene de prepararse con disciplina, hacer un trabajo de investigación riguroso para enfrentar la tarea pedagógica (Freire 2010, 46; 1997, 30).

De esta manera, los retos serán establecidos en conjunto: los estudiantes estarán - entre otras cosas- produciendo preguntas y manifestando sus dudas; el profesor trabajará primordialmente en la construcción de un contexto en el que dichas preguntas y dudas se generen y los dos estarán trabajando para encontrar disoluciones, en términos de Wittgenstein $(2009,133)$, algo que me parece posible, y además importante, hacer en el aula, pues cabe la posibilidad de que no todos los problemas que se planteen sean válidos $y$, en ese sentido, no a todos hay que buscarles una solución. En los casos en que los cuestionamientos nacen de problemáticas sociales seguramente encontrarán respuestas y, dependiendo del caso, se verán motivados a transformar su entorno (Smith-Maddox y Solórzano 2002). En esto consiste básicamente la educación problematizadora o liberadora. Mediante esta se buscará superar la contradicción educador-educando, pues el diálogo rompe la estructura vertical característica de la concepción bancaria. Así, la diferencia crucial entre la concepción bancaria y la educación problematizadora es que solo esta última se encarga de superar la contradicción educador-educando, lo cual conduce a la liberación de las dos partes.

\section{La contradicción de Freire}

Con lo anterior se ha intentado presentar de manera sintética los fundamentos teóricos sobre los que descansa la pedagogía de la liberación propuesta por Freire; fundamentos que, como ya se ha dicho, permean 
toda su obra. En lo que sigue, se mostrará que la propuesta freireana cae en una contradicción que afecta de manera importante su sistema. Para mostrar el problema, retomaré algunos puntos ya mencionados y, con el fin de ser riguroso, construiré la contradicción a partir de citas tomadas principalmente de la Pedagogía del oprimido (Freire 2005).

De acuerdo con Freire, en la educación bancaria, el educador es el opresor, mientras que el educando es el oprimido. Dice él:

Los educandos, alienados a su vez, a la manera del esclavo, en la dialéctica hegeliana, reconocen en su ignorancia la razón de la existencia del educador pero no llegan, ni siquiera en la forma del esclavo en la dialéctica mencionada, a descubrirse como educadores del educador (Freire 2005, 79).

Y más adelante dice:

Los llamados marginados, que no son otros sino los oprimidos, jamás estuvieron fuera de. Siempre estuvieron dentro de. Dentro de la estructura que los transforma en "seres para otro". Su solución, pues, no está en el hecho de "integrarse" de "incorporarse" a esta estructura que los oprime, sino transformarla para que puedan convertirse en "seres para sí". Obviamente, no puede ser éste el objetivo de los opresores. De ahí que la "educación bancaria", que a ellos sirve, jamás pueda orientarse en el sentido de la concienciación de los educandos (Freire 2005, 82).

Freire sostiene que, en la relación opresor-oprimido, es el oprimido quien tiene la responsabilidad de liberarse. Dice él: "Ahí radica la gran tarea humanista e histórica de los oprimidos: liberarse a sí mismos y liberar a los opresores" (Freire 2005, 41). Y más adelante: "Es por esto por lo que sólo los oprimidos, liberándose, pueden liberar a los opresores. Éstos, en tanto clase que oprime, no pueden liberar, ni liberarse" (Freire 2005, 57).

En síntesis, el argumento podría ser el siguiente: el opresor está incapacitado para liberar al otro, así como para liberarse a sí mismo. La 
tarea de los oprimidos es liberarse a sí mismos y liberar a los opresores. En la educación bancaria el educando es oprimido por el educador. Por tanto, siendo coherentes con la propuesta freireana, el educando será quien luche por su liberación y la del educador.

No obstante, al contrario de lo que podría esperarse, es el educador quien transforma el aula para liberarse y, con ello, liberar al educando, deviniendo "educador-educando" y permitiendo al educando devenir "educando-educador: $\mathrm{Al}$ respecto dice Freire:

Para realizar esta concepción de la educación como práctica de la libertad, su dialogicidad empieza, no al encontrarse el educador-educando con los educando-educadores en una situación pedagógica, sino antes, cuando aquél [el educador] se pregunta en torno a qué va a dialogar con éstos. Dicha inquietud en torno al contenido del diálogo es la inquietud a propósito del contenido programático de la educación (Freire 2005, 113).

En contraste con lo anterior, el educador bancario diseña el programa en el que se basará su curso. En este sentido, si el educador bancario se hace una pregunta en el momento de trabajar en el contenido programático, la responderá él mismo (dada su antidialogicidad) organizando su programa.

Para el educador-educando, en cambio, el contenido programático de la educación es el resultado de un trabajo mediante el cual él organiza y sistematiza la información que sus estudiantes le han entregado en forma desordenada. Esta idea la construye Freire de acuerdo con una cita que toma de Malraux: "Debemos enseñar a las masas con precisión lo que hemos recibido de ellas con confusión" (André Malraux, Antimémoires)" (Freire 2005, 113, nota 54).

La contradicción que quiero establecer podría también presentarse en los siguientes términos: la Pedagogía del oprimido está dirigida a los oprimidos porque los opresores no la podrían comprender o, mejor, no les interesa comprenderla; más bien lo contrario, estarían interesados en impedir que se comprendiera. En la relación educador-educando, el educador es opresor, bajo la estructura de la educación bancaria. Por 
ello, la obra de Freire estaría dirigida a los educandos. No obstante, esta está dirigida a los educadores, que en el aula ocupan un poder opresor. Por ello, se concluye que la Pedagogía del oprimido es un escrito dirigido a los opresores.

\section{Asumiendo la contradicción}

Hasta este punto se ha intentado demostrar que la Pedagogía del oprimido está dirigida al educador y, en este sentido, al opresor. También se ha afirmado que, para superar la contradicción educador-educando, al primero - al educador- le corresponde diseñar un programa en el que se le dé un lugar participativo al estudiante, uno en el que el diálogo (en el sentido ya definido) desempeñe un papel central. El educador bancario carece del interés o de las facultades requeridas para diseñar un programa de esta naturaleza; tal responsabilidad recae, para Freire, en el educador humanista. Ahora bien, ¿quién es el educador humanista?, ¿dónde se forma?, ¿cómo se forma?, ¿quién lo forma?, ¿qué criterios debe cumplir? Estas preguntas son importantes en especial en el momento de poner en práctica la propuesta freireana. Bartlett (2005), por ejemplo, encuentra que los docentes que pretenden seguir las enseñanzas de Freire en Brasil no conocen a fondo la propuesta teórica del pensador brasileño, toda vez que no han leído y discutido rigurosamente su obra, por lo cual su trabajo se reduce de alguna manera a repetir sin mayor esfuerzo crítico algunas frases célebres del pedagogo (351).

El pensador brasileño está planteando una crítica contundente a la educación tradicional y, en este sentido, está luchando por romper con su statu quo; digo luchando en sentido literal, toda vez que parte importante de su obra la realizó en interacción con los "condenados de la tierra". Siendo esta la situación, las anteriores preguntas cobran relevancia, pues, dadas las condiciones, no resulta sencillo encontrar educadores humanistas que se encarguen de asumir con rigor la responsabilidad que les asigna Freire.

El pensador brasileño nos dice que el oprimido debe liberarse a sí mismo para, luego, liberar al opresor, lo cual implica, por un lado, una transformación personal y, por el otro, una transformación de las condiciones en las que se vive, esto es, del mundo. Transformación que se 
dará en comunión, mediante el diálogo. Ahora que sabemos que, en el aula tradicional, es el opresor quien tiene la responsabilidad de la liberación, lo anterior implica que él deberá sufrir una transformación que le permita liberarse y, con ello, liberar a los oprimidos, que serían sus estudiantes. ¿Cómo se lleva a cabo esta liberación? La respuesta a esta pregunta implica dilucidar cómo el educador bancario deviene educador humanista.

Si diéramos por sentado que existe el educador humanista, como pareciera hacerlo Freire en su Pedagogía del oprimido, toda su propuesta perdería relevancia. En efecto, ¿para qué insistir en la liberación si aquellos a los que iría dirigida esta propuesta ya están liberados?

\section{El colono como descolonizador, lectura freireana (y antifreireana)}

En la sección "La contradicción de Freire", se hizo una reinterpretación de la propuesta freireana para mostrar que el opresor es el encargado de iniciar su liberación y, con ello, la del oprimido. Si aplicáramos esta reflexión al tema de la colonialidad, diríamos que es el colono quien tiene la responsabilidad de iniciar la lucha por su liberación y la del colonizado, lo cual no es algo difícil de pensar. En la historia, muchos de los que han liderado la emancipación de los oprimidos han sido personas que pertenecen a la clase opresora y que, ayudados por el pueblo, logran el objetivo de la liberación. Ahora bien, normalmente el opresor que se solidariza con los oprimidos logra su propósito gracias a que cunde un malestar en el pueblo que facilita en gran medida la aceptación del discurso del "opresor solidario", lo cual produce la movilización general. Solo mediante la movilización del pueblo, el opresor logra finalmente el objetivo de la liberación. Robespierre, Simón Bolívar, George Washington, entre otros, podrían servir como ejemplo de esta interpretación.

Ahora bien, es posible que el sujeto $S$ que es opresor en el escenario $A$, sea un oprimido en el escenario $B$. Según esto, podría decirse que el sujeto $S$, que es opresor en el escenario $A$, busca la liberación de su comunidad bajo su papel de oprimido en el escenario $B$. Aplicado esto al punto que nos interesa, podría decirse que el colono busca la liberación, pero no en cuanto colono, sino en cuanto colonizado. Puesto así, no 
estaríamos en un escenario muy distinto del que nos plantea Freire en su Pedagogía del oprimido. Lo que a mí me parece interesante pensar, en contraste con la propuesta freireana, es el caso en el que el opresor en cuanto opresor - el colono en cuanto colono- inicia la lucha por su liberación y la de los oprimidos. En este caso, la liberación se podrá llevar a cabo, pienso, gracias a que hay una condición de opresión de la que ambos (opresor y oprimido) quieren salir porque, de una u otra manera, están en busca de su humanización y la de sus congéneres.

Claro está que lo dicho puede ser utilizado maquiavélicamente. Asumamos que el opresor se presenta ante el pueblo como alguien interesado en luchar por la liberación de los dos (opresor y oprimido). Puede suceder que él no esté actuando en favor de ambos (opresor y oprimidos), sino solo en favor de sí mismo. Así, se valdrá engañosamente de las necesidades del pueblo para lograr sus fines personales. Permítaseme, para ejemplificar lo anterior, hacer una sintética digresión sobre el conflicto armado colombiano. En este cada una de las partes está pensando en derrotar o castigar a la otra, no en humanizarse con la otra. Ultraderecha, paramilitares, guerrillas, izquierda, cada ala está interesada en ello, en derrotar o en castigar al que ve como su contendiente. El pueblo, de igual manera, está interesado en que alguna de las partes reciba un castigo, ya sea la guerrilla, los paramilitares, la ultraderecha o la izquierda. Solo una pequeña fracción está pensando en la humanización de todos.

Entonces, el problema no es solo que el opresor se valga maquiavélicamente de las malas condiciones en las que vive su pueblo para obtener un beneficio propio; el problema además es que el pueblo mismo no esté buscando la humanización, sino la destrucción de aquel a quien considera su antagonista. Esta interacción social en la que no se busca la humanización, sino la destrucción de otros seres humanos, refleja parcamente lo que Freire denomina la contradicción opresor-oprimido: el oprimido para salir de su condición de opresión deviene opresor para destruir al "enemigo", sin percatarse de que con esta destrucción está deshumanizándose a sí mismo, es decir, está siendo como su enemigo (está actuando o está permitiendo que se actúe como actuaría su enemigo), está produciendo - o está permitiendo que se produzca - terror. 
De todo lo anterior podemos concluir que solo cuando el colonizador y el colonizado se unen para luchar en favor de la humanización de todos, se logra la liberación. Freire estaría de acuerdo con esta conclusión. Lo que no estaría dispuesto a aceptar, y que es lo que se ha intentado mostrar en el presente documento, es que quien asume inicialmente la lucha por la humanización es el opresor y que esto ocurre tanto en el aspecto pedagógico como en el aspecto social.

Para evitar ambigüedades en lo antedicho, quiero terminar diciendo que en este texto no he argumentado en contra de la "contradicción opresor-oprimido". Lo que sí he hecho es mostrar la inconsistencia que existe en la solución que Freire propone a ella.

\section{Referencias bibliográficas}

Aronowitz, Stanley. 1993. "Paulo Freire's radical democratic humanism". En Paulo Freire: A critical encounter, eds. Peter Leonard y Peter McLaren, 8-24. Nueva York: Routledge.

Bartlett, Lesley. 2005. "Dialogue, knowledge, and teache-student relations: Freirean pedagogy in theory and practice". Comparative Education Review 3: 344-364.

Beckett, Kelvin Stewart. 2013. "Paulo Freire and the concept of education". Educational Philosophy and Theory 1: 49-62.

Earwaker, John. 1973. "RS Peters and the Concept of Education”. Journal of Philosophy of Education 2: 239-259.

Beckett, Kelvin. 2011. "Culturally relevant teaching and the concept of education". Philosophical Studies in Education 42: 65-75.

Freire, Paulo. 1970. La concientización. Caracas: Instituto Agrario Nacional.

Freire, Paulo. 1984. La importancia de leer y el proceso de liberación. México. Siglo XXI.

Freire, Paulo. 1997. Pedagogía de la autonomía: saberes necesarios para la práctica educativa. México: Siglo XXI.

Freire, Paulo. 2005. Pedagogía del oprimido. México: Siglo XXI.

Freire, Paulo. 2010. Cartas a quien pretende enseñar. México: Siglo XXI. 
Freire, Paulo y Donaldo Macedo. 1987. Literacy: reading the word and the world. South Hadley, MA: Bergin \& Garvey.

Freire, Paulo, Moacir Gadotti y Sérgio Guimarães. 1987. Pedagogía: diálogo e conflicto. Buenos Aires: Cinco.

Giroux, Henry A. 1993. "Paulo Freire and the politics of postcolonialism", en Paulo Freire: a critical encounter, eds. Peter McLaren y Peter Leonard. Londres: Routledge.

Kant, Immanuel. 1784/1978. ¿Qué es la Ilustración?, en Filosofía de la historia, trad. Ímaz Eugenio, 25-38. México: Fondo de Cultura Económica.

Margonis, Frank. 2003. "Paulo Freire and post-colonial dilemas". Studies in Philosophy and Education 2, 145-156.

McLaren, Peter. 2000. Che Guevara, Paulo Freire, and the pedagogy of revolution. Lanham: Rowman \& Littlefield Publishers.

Smith-Maddox, Renée y Daniel G. Solórzano. 2002. "Using critical race theory, Paulo Freire's problem-posing method, and case study research to confront race and racism in education". Qualitative Inquiry 1: 66-84.

Walsh, Catherine E., ed. 2013. Pedagogías decoloniales: prácticas insurgentes de resistir, (re) existir y (re) vivir. T. I. Quito: Abya Yala.

Wittgenstein, Ludwig. 2009. Philosophical investigations, eds. y trad. P. M. S. Hacker y Joachim Schulte. Oxford: Wiley-Blackwell. 